NASA/TM-2005-213385

\title{
Dual Purpose Simulation: New Data Link Test and Comparison With VDL-2
}

Daryl C. Robinson

Glenn Research Center, Cleveland, Ohio 
Since its founding, NASA has been dedicated to the advancement of aeronautics and space science. The NASA Scientific and Technical Information (STI) Program Office plays a key part in helping NASA maintain this important role.

The NASA STI Program Office is operated by Langley Research Center, the Lead Center for NASA's scientific and technical information. The NASA STI Program Office provides access to the NASA STI Database, the largest collection of aeronautical and space science STI in the world. The Program Office is also NASA's institutional mechanism for disseminating the results of its research and development activities. These results are published by NASA in the NASA STI Report Series, which includes the following report types:

- TECHNICAL PUBLICATION. Reports of completed research or a major significant phase of research that present the results of NASA programs and include extensive data or theoretical analysis. Includes compilations of significant scientific and technical data and information deemed to be of continuing reference value. NASA's counterpart of peerreviewed formal professional papers but has less stringent limitations on manuscript length and extent of graphic presentations.

- TECHNICAL MEMORANDUM. Scientific and technical findings that are preliminary or of specialized interest, e.g., quick release reports, working papers, and bibliographies that contain minimal annotation. Does not contain extensive analysis.

- CONTRACTOR REPORT. Scientific and technical findings by NASA-sponsored contractors and grantees.
- CONFERENCE PUBLICATION. Collected papers from scientific and technical conferences, symposia, seminars, or other meetings sponsored or cosponsored by NASA.

- SPECIAL PUBLICATION. Scientific, technical, or historical information from NASA programs, projects, and missions, often concerned with subjects having substantial public interest.

- TECHNICAL TRANSLATION. Englishlanguage translations of foreign scientific and technical material pertinent to NASA's mission.

Specialized services that complement the STI Program Office's diverse offerings include creating custom thesauri, building customized databases, organizing and publishing research results ... even providing videos.

For more information about the NASA STI Program Office, see the following:

- Access the NASA STI Program Home Page at http://www.sti.nasa.gov

- E-mail your question via the Internet to help@sti.nasa.gov

- Fax your question to the NASA Access Help Desk at 301-621-0134

- Telephone the NASA Access Help Desk at 301-621-0390

- Write to:

NASA Access Help Desk

NASA Center for AeroSpace Information 7121 Standard Drive

Hanover, MD 21076 
NASA/TM-2005-213385

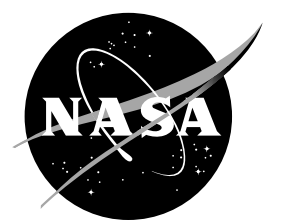

\section{Dual Purpose Simulation: New Data Link Test and Comparison With VDL-2}

Daryl C. Robinson

Glenn Research Center, Cleveland, Ohio

Prepared for the

21st Digital Avionics Systems Conference (DASC 2002)

cosponsored by the American Institute of Aeronautics and Astronautics and the Institute of Electrical and Electronics Engineers

Irvine, California, October 27, 2002

National Aeronautics and

Space Administration

Glenn Research Center 


\section{Acknowledgments}

I acknowledge Mr. Robert Kerczewski for recruiting me for this area of research and for funding it. I also acknowledge the efforts of my summer interns, Proloy Bhattacharyya, University of California, Irvine, and Steve Drescher, Ohio State University. Proloy built the network used in these simulations according to my specifications. Steve researched and generated, according to my specifications, all of the aircraft trajectories used in the simulations.

They wrote process models and $\mathrm{C}$ programs to validate their very

good work, thereby allowing me to concentrate on writing all of the process models used in the simulation.

Available from

NASA Center for Aerospace Information 7121 Standard Drive

Hanover, MD 21076
National Technical Information Service 5285 Port Royal Road Springfield, VA 22100

Available electronically at http:/ /gltrs.grc.nasa.gov 


\title{
DUAL PURPOSE SIMULATION: NEW DATA LINK TEST AND COMPARISON WITH VDL-2
}

\author{
Daryl C. Robinson \\ National Aeronautics and Space Administration \\ Glenn Research Center \\ Cleveland, Ohio 44135
}

\begin{abstract}
While the results of this paper are similar to those of previous research [1], in this paper technical difficulties present there [1] are eliminated, producing better results, enabling one to more readily see the benefits of Prioritized CSMA (PCSMA). A new analysis section also helps to generalize this research so that it is not limited to exploration of the new concept of PCSMA. Commercially available network simulation software, OPNET version 7.0, simulations are presented involving an important application of the Aeronautical Telecommunications Network (ATN), Controller Pilot Data Link Communications (CPDLC) over the Very High Frequency Data Link Mode 2 (VDL-2). Communication is modeled for essentially all incoming and outgoing nonstop air traffic for just three United States cities: Cleveland, Cincinnati, and Detroit. The simulation involves 111 Air Traffic Control (ATC) ground stations, 32 airports distributed throughout the U.S., which are either sources or destinations for the air traffic landing or departing from the three cities, and also 1,235 equally equipped aircraft — taking off, flying realistic free-flight trajectories, and landing in a 24-hr period. Collision-less PCSMA is successfully tested and compared with the traditional CSMA typically associated with VDL-2. The performance measures include latency, throughput, and packet loss. As expected, PCSMA is much quicker and more efficient than traditional CSMA. These simulation results show the potency of PCSMA for implementing low latency, high throughput and efficient connectivity. Moreover, since PCSMA outperforms traditional CSMA, by simulating with it, we can determine the limits of performance beyond which traditional CSMA may not pass. We are testing a new and better data link that could replace CSMA with relative ease. Work is underway to drastically expand the number of flights to make the simulation more representative of the National Aerospace System.
\end{abstract}

\section{Introduction}

Due to a lack of surveillance and communications coverage, in many parts of the world, aircraft are forced to fly routes and maintain separations that are inefficient from both a fuel and scheduling perspective. The total loss to airlines due to these inefficiencies is measured in billions of dollars. The problem is expected to rapidly mushroom given the expected user demand for scheduled air service. The Advanced Air Transportation Technologies (AATT) Program has been instituted to develop new technologies that enable free-flight, an operating system in which pilots have the freedom to select their path and speed in real-time [2].

To implement free-flight, CPDLC is viewed as very important for the new aeronautical communications infrastructure. CPDLC will eliminate voice-only communications.

In the simulations of this paper, realistic ground-to-air and air-to-ground communications are achieved by assuming an effective, intact terrestrial network and by treating planes as traffic generators and sinks, in a manner analogous to the transparent usage of a traffic injector or "sniffer" in a network. Further, the idea of PCSMA is reintroduced and successfully tested through simulation. PCSMA trades off the use of an additional radio frequency in order to implement efficient CSMA without collisions. The benefit gained of efficient, collisionless CSMA is that the inefficiencies introduced by wasted time division multiple access (TDMA) time slots may be avoided.

\section{Simulation Focus}

The primary focus of the simulations is to examine the behavior of ATC communications over VDL-2 in an aviation scenario involving a substantial amount of air and communications traffic. Both weather and terrain were ignored, and 
the simulation assumes a spherical earth. Indirect communication is not implemented in this "OPNET" (network simulation software tool) simulation. Two nodes may communicate only when they are in direct line-of-sight, so extending the range of ground stations by bouncing signals off of the ionosphere is not permitted here. All incoming and outgoing nonstop air traffic for three cities was simulated. Given the time constraints for this research and the scope of this simulation, it was not desirable to simulate the communications architecture for the entire OSI stack. Since the media access control layer (MAC) layer is especially important in broadcast media, largely determining the limit of performance, heavy emphasis was placed upon the data link layer, VDL-2. These simulations do not model the presentation, session, transport, or network layers, as it was of most interest to simulate the VDL-2 data link layer, which is being deployed. The most important use of these simulations is to test PCSMA.

\section{Simulation Overview}

As previously stated, the simulation involves 1,235 flights, 111 ATC transceivers or ground stations, and 32 airports. The take off, arrival, and flight times for one day were based on real flight plans obtained from the airports. Instead of actually modeling the fact that one plane may make several flights, a separate OPNET mobile airplane node is used for each flight. For reasons discussed later, CPDLC messages in these simulations have a 5,000 bit mean file size. CPDLC file sizes are chosen according to the normal distribution. CPDLC messages have a variance of 2,500 bits. They have a mean interarrival time of $6 \mathrm{~min}$, using the exponential distribution. All CPDLC transceivers operate at $136 \mathrm{MHz}$ with a $10 \mathrm{KHz}$ bandwidth.

\section{Message Length}

The maximum CPDLC packet size is 8,312 bits. In these simulations, however, we use a 5,000 bit message length and compensate by increasing the frequency of CPDLC communication. However, for many years, it is unlikely that CPDLC messages will use packets as long as 8,312 bits. The most probable packet length is subject to determination. Since that precise value was not known at the time of these simulations, we settled on the mean value of 5,000 bits.

\section{Ground Stations}

It was not intended to perfectly replicate the National Aerospace System (NAS) in these simulations, but to provide a data communications environment in the simulation similar to that in the NAS. Consequently we did not require an exact distribution of ground stations. Instead, for research purposes, we distributed them uniformly throughout the United States. A $100 \mathrm{~m}$ ground station may maintain direct line-of-sight communication with an airplane having an average altitude of $3.43 \mathrm{mi}$. for about $300 \mathrm{~km}$. We used an average spacing of $290 \mathrm{~km}$ between adjacent ground stations to ensure continuous air to ground and ground to air communications. The ATC tower at Hopkins is $199 \mathrm{ft}=60.93 \mathrm{~m}$ in height. The simulation approximates the altitude of typical VDL ground stations as half that value, $30.47 \mathrm{~m}$. There are 111 ground stations in the simulation. Additionally, there is an air traffic control tower at each of the 32 airports. Figure 1 shows a view of the 32 airports and 111 ground stations involved in the simulation. The ground stations are capable of detecting the presence of a plane and only send CPDLC messages if there is a plane within its $290 \mathrm{~km}$ airspace to receive them. Due to the functioning of PCSMA, the ground stations are coordinated and produce no uplink interference.

\section{Details}

Each airport is initially stocked with many planes, which will take off for one of the remaining 31 airports during the course of the $24 \mathrm{hr}$ simulation. Again, all simulated flights are nonstop. Each ground station, including air traffic control towers, consists of a CPDLC transceiver. Each airplane has identical communications architecture. CPDLC exists only between aircraft and ground stations. The CPDLC transmission node architecture is shown in fig. 2.

In fig. 2, "gen" is a clocked generator of packets. "q_1" is a queue to buffer the packets. " $p \_0$ " is a processor module, which decides whether to leave the packets in the queue or to forward them on to the radio transmitter through pt_0. 


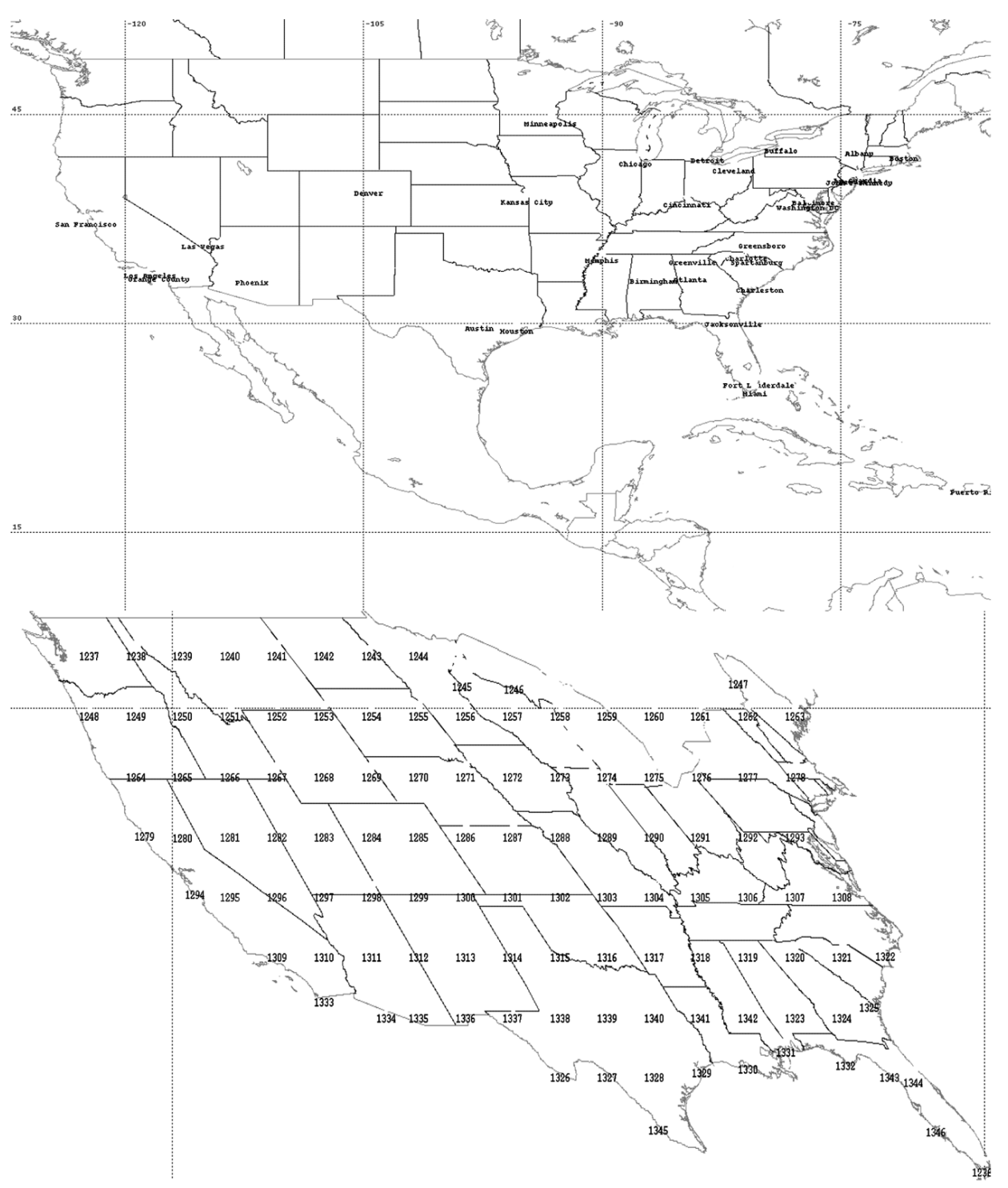

Figure 1. 32 airports (top) and 111 ground stations.

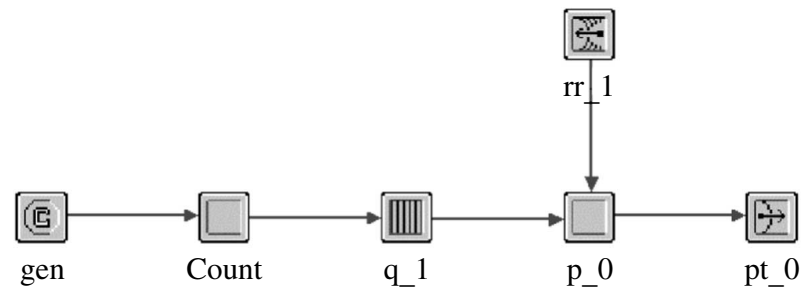

Figure 2: CPDLC node architecture. 
Airline officials provided us with typical flight altitudes as a function of distance traveled for various ranges. A typical plot of a trajectory profile is shown in fig. 3 .

Cruise altitudes used in the simulation depend on the range of the flight. The histogram, in fig. 4, of the number of planes in flight, as a function of simulation time in minutes is based on the actual data from the airports and is not an output of simulation. This histogram can be used to understand traffic loading in the simulation. Air traffic begins $1 \mathrm{hr} 10 \mathrm{~min}$ into the simulation and continues throughout the $24 \mathrm{hr}$ simulation. From the airport data, the average number of planes flying is 90.8. The peak traffic is at $(60 \mathrm{~s} / \mathrm{min})(910 \mathrm{~min})=$ $54,600 \mathrm{~s}$ or $3: 10$ p.m.

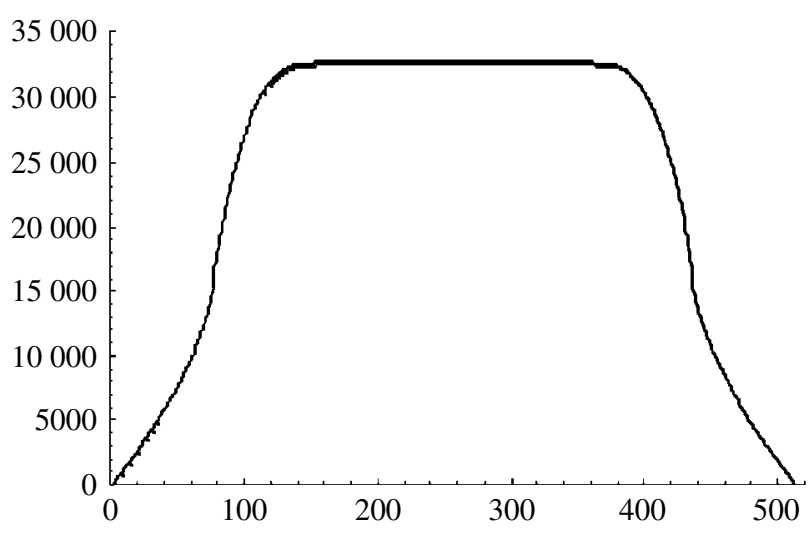

Figure 3: Flight trajectory profile: Cleveland to Albany. Altitude (ft) vs. time (sec/10).

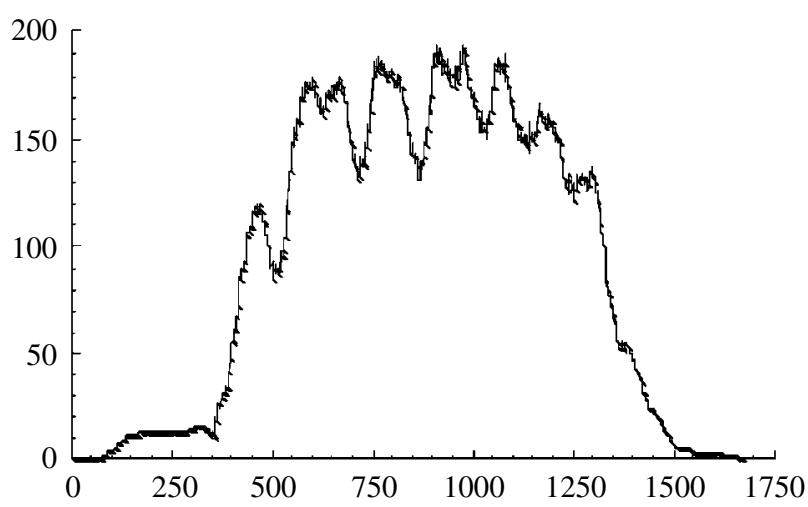

Figure 4: Number of planes aloft vs. time (min).

\section{CSMA Discussion}

A single communications frequency is used for radio frequency conservation. Just as in CB radio, one party communicates at a time. Just as east coast truckers may talk without interference from west coast truckers, in these simulations, different lineof-sight groups can communicate on the same frequency simultaneously without interference.

CSMA is contention-based. All parties listen to the channel. When the channel is free, many parties contend for it until after a random back-off time. Eventually, one party gains control of the channel for uninterrupted usage. Because of the contention process, collisions can be inefficient.

\section{PCSMA}

In PCSMA, each communications party is assigned a priority for transmission, based on its need to transmit. In these simulations, transmission priority is granted on a first come, first served basis. If the medium is busy, each transmitter receives a waiting ticket. When its number comes up, the transmitter takes its turn. When the channel is free, instead of a random back-off time elapsing before one node gains usage of the channel, in PCSMA, the node with the next higher priority begins uninterrupted transmission immediately in an orderly fashion, without contention. In studying PCSMA, we simultaneously accomplish two purposes. We can test this new idea and also obtain the upper bound for performance of VDL-2 with the given traffic of the simulation. Because of its retransmissions and random back-off time, VDL-2 should not perform as well as PCSMA.

\section{Details}

It is assumed that in a real implementation of the idea of PCSMA, both planes and ground stations include a connection transmission (cnctrans) transmitter. Much like an Automatic Dependent Surveillance-Broadcast Mode (ADS-B) transmitter, this transmitter would broadcast cnctrans packets at regular intervals on a separate frequency. The cnctrans packets are nearly length zero and contain the unique source identification code (srcid) of the transmitting node. They may also contain a time stamp and the transmission time remaining for that node. When a node receives a 
cnctrans packet, it updates an array of cnctrans information from its neighbors. If a cnctrans packet has not been received from a node in $\Delta t$, it is assumed unreachable. When a node seizes the channel, all nodes wait until it is finished. Each node waits until the farthest neighbor of the last transmitting node has received the transmission. When the transmission is finished, the next node begins orderly transmission. In these simulations, the cnctrans packets do not collide since they are of zero length.

\section{Simulation Results and Analysis}

\section{Results}

There were six simulation runs. I and IV, 6 min mean CPDLC interarrival time; II and V, 3 min mean CPDLC interarrival time; and III and VI, 1.5 min mean CPDLC interarrival time.

\begin{tabular}{|l|c|c|c|}
\hline Run & $\begin{array}{c}\text { Access } \\
\text { Scheme }\end{array}$ & $\mathrm{D}$ & $(\mathrm{T}, \mathrm{R})$ \\
\hline I & $\mathrm{X}$ & 0.3182 & $(38412,34012)$ \\
\hline II & $\mathrm{X}$ & 0.3184 & $(77760,61807)$ \\
\hline III & $\mathrm{X}$ & 0.3188 & $(156512,104252)$ \\
\hline IV & PCSMA & 0.3582 & $(38529,38529)$ \\
\hline V & PCSMA & 0.4039 & $(77140,77140)$ \\
\hline VI & PCSMA & 0.5772 & $(154304,154304)$ \\
\hline
\end{tabular}

where all transceivers are set at $31.5 \mathrm{Kbps}$ [1],

$\mathrm{X}=$ No access scheme

$\mathrm{D}=$ Mean end-to-end (ETE) delay of CPDLC packets

$\mathrm{T}=$ Number of CPDLC messages transmitted

$\mathrm{R}=$ Number of CPDLC messages received

Plots of CPDLC transmitted and received packets for Runs I to VI are shown in figs. 5 to 10 . Included in those figures are plots of ETE delays for each run.

Only the runs using PCSMA successfully transmitted all CPDLC packets with zero packet loss. These results show that this implementation of the idea of prioritized, collision-less CSMA works. Moreover, a comparison between the performance latencies in these simulations and the 95th percentile ETE delay requirement of $3 \mathrm{sec}$ [1] shows that PCSMA is remarkably quick and efficient.
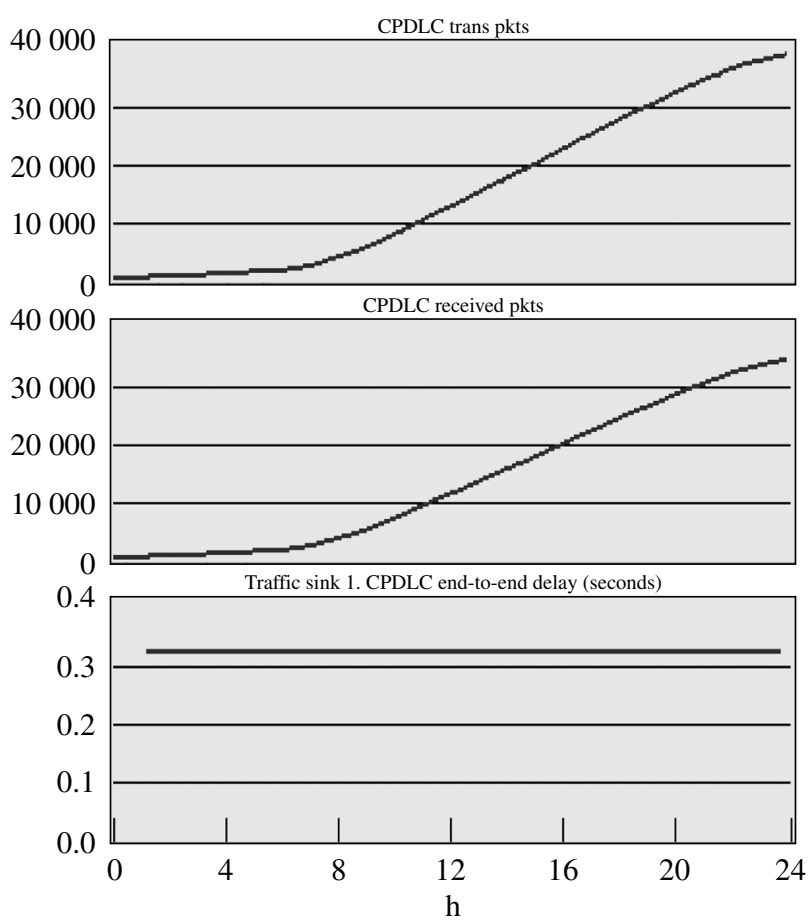

Figure 5: CPDLC packet reception and delay, I.

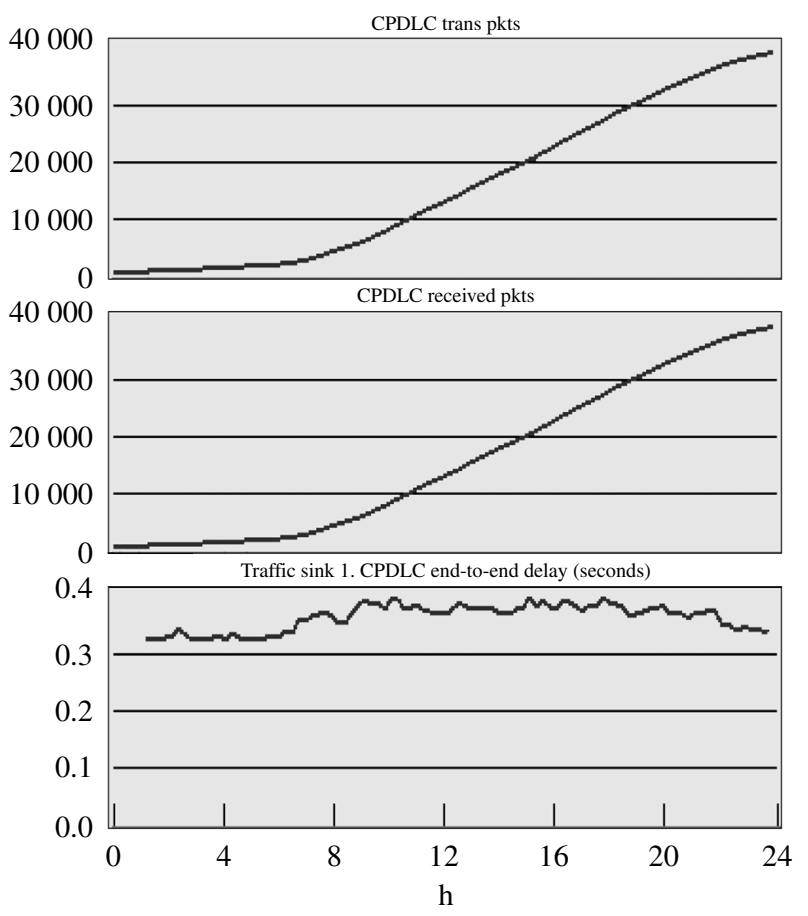

Figure 6: CPDLC packet reception and delay, IV. 

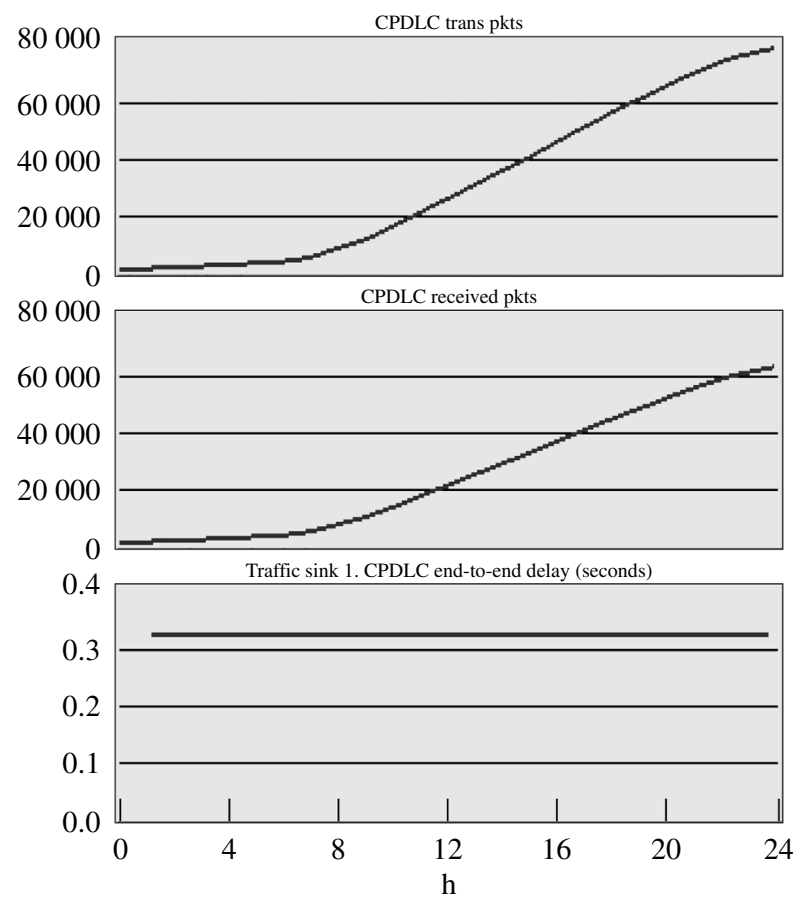

Figure 7: CPDLC packet reception and delay, II.

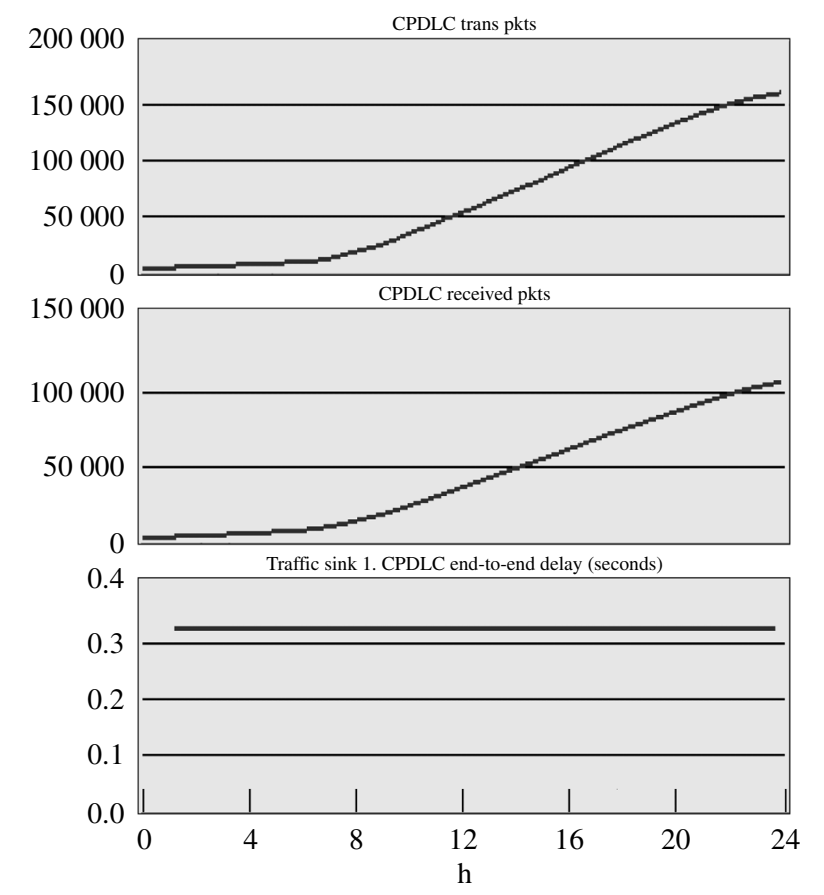

Figure 8: CPDLC packet reception and delay, III.

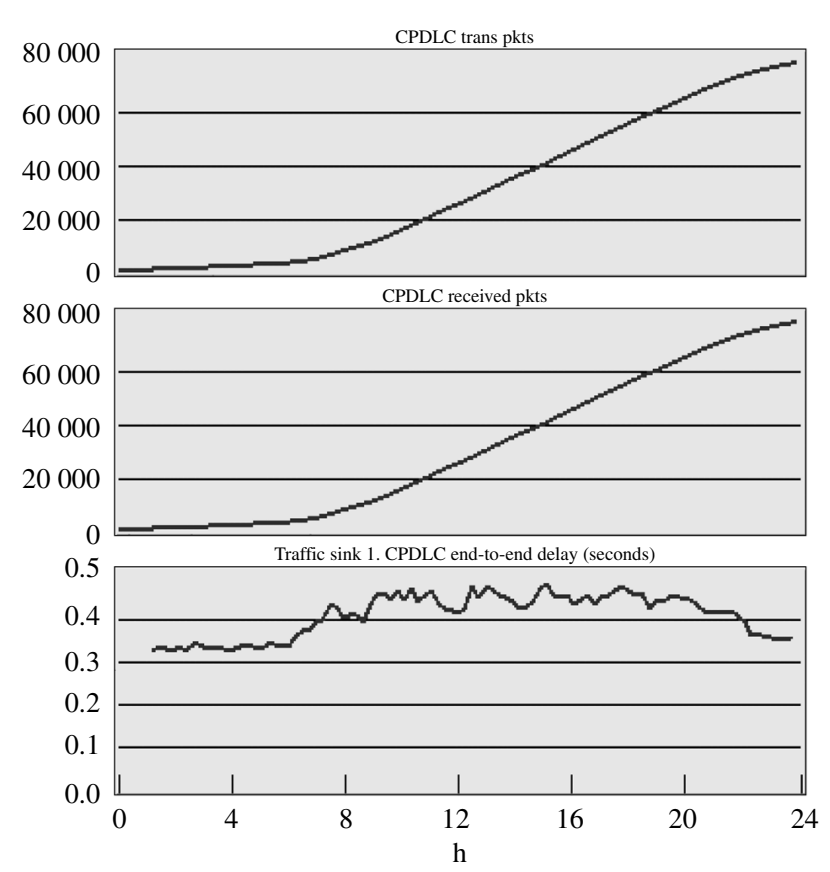

Figure 9: CPDLC packet reception and delay, V.

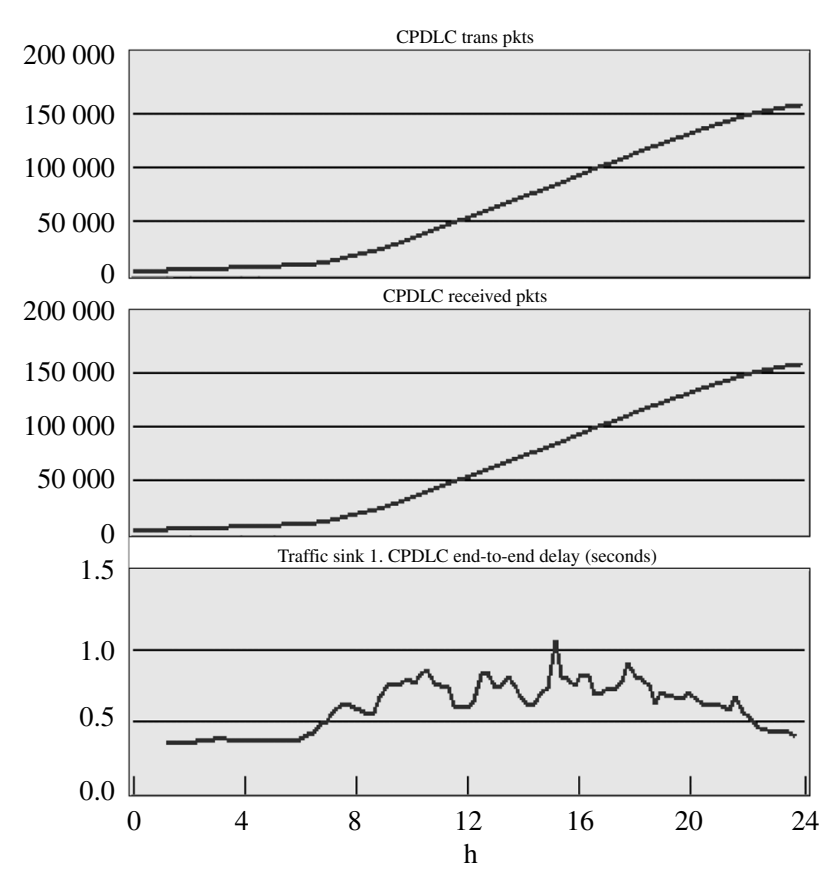

Figure 10: CPDLC packet reception and delay, VI. 


\section{Retransmission Analysis}

In this section, we derive a relationship bounding the performance of traditional VDL-2 involving retransmissions with that of a freely transmitting (FT) network (one in which no access scheme is used). Let $p$ be the probability of a collision occurring in the simulation. For example, in Run III, 156,512 messages were transmitted, while 104,252 were received. The probability of collision for the simulation is therefore $1-104,252 / 156,512=33.4$ percent. Let D' and D be the average ETE delays encountered by a message in a traditional VDL-2 network involving retransmissions, and in an FT network, respectively. Let "RT" represent "retransmission," and "RTD," "retransmission delay for exactly i collisions or, equivalently, retransmissions before successful transmission." Then

$$
\begin{aligned}
& (1) D^{\prime}=\left(D+D_{s}\right)(1-p)+R T D_{1} p(\# R T=1)+ \\
& R T D_{2} p(\# R T=2)+R T D_{3} p(\# R T=3)+\ldots,
\end{aligned}
$$

where

(2) $\mathrm{p}(\# \mathrm{RT}=1)+\mathrm{p}(\# \mathrm{RT}=2)+\mathrm{p}(\# \mathrm{RT}=3)+\ldots$

$=\mathrm{p}=\mathrm{p}(\#$ coll = 1) $+\mathrm{p}(\#$ coll = 2) $+\mathrm{p}(\#$ coll = 3)

$+\ldots$

$\mathrm{D}_{\mathrm{s}}$ is defined below.

We may verify (2) as follows:

$$
\begin{aligned}
& \text { Let } Q=p(1-p)+p^{2}(1-p)+p^{3}(1-p)+\ldots= \\
& (1-p)\left(p+p^{2}+p^{3}+\ldots\right)=(1-p) s . \\
& s=p /(1-p) . \text { So } Q=p, \text { as expected. }
\end{aligned}
$$

In terms of performance measurement, we will be conservative for PCSMA and generous with respect to VDL-2. That is to say, to account for the delays of VDL-2, we will include only these delays: startup delay, processing delay, exponential backoff delay, and propagation delay. Much to the credit of PCSMA, there are other VDL-2 delays such as TM1, T1, and T2 [3], but since they complicate the performance assessment calculation, they will not be included. Here we will define and quantify the startup delay, $\mathrm{D}_{\mathrm{s}}$. The startup delay exists in a VDL-2 network because of the p-persistent CSMA that it uses. When a frame is created, it is transmitted with probability p' and deferred with probability $1-p$ '. To quantify the average delay experienced by a frame before it is actually transmitted, we perform the following calculation:

Let $\mathrm{T}$ be the frame transmission time.

The expected time that the frame is deferred before transmission is:

$$
\begin{aligned}
& \mathrm{D}_{\mathrm{s}}=\mathrm{T}\left(1-\mathrm{p}^{\prime}\right)+2 \mathrm{~T}\left(1-\mathrm{p}^{\prime}\right)^{2}+3 \mathrm{~T}\left(1-\mathrm{p}^{\prime}\right)^{3}+ \\
& \ldots=\mathrm{T} \operatorname{Sum}\left[\mathrm{j}\left(1-\mathrm{p}^{\prime}\right)^{\mathrm{j}},\{\mathrm{j}, 1, \text { Infinity }\}\right]
\end{aligned}
$$

Let p" $=1-$ p'. Then

$$
\mathrm{D}_{\mathrm{s}}=\mathrm{T} \mathrm{p}, \mathrm{T}^{\prime \prime}+2 \mathrm{~T}+3 \mathrm{~T} \mathrm{p}^{, 3}+\ldots
$$

This is an arithmetic-geometric series, which may be summed by integrating with respect to p", summing, and then differentiating with respect to p" (all summations herein are Mathematicafriendly and may be verified by cutting and pasting them into Mathematica, using the carat $\left({ }^{\wedge}\right)$ to represent exponentiation instead of a superscript, and "unpriming" primed variables):

$$
\begin{aligned}
& \mathrm{D}_{\mathrm{s}}=\mathrm{T} \text { p' } \operatorname{Sum}\left[\mathrm{i} \mathrm{p}^{, \mathrm{i}^{-1}},\{\mathrm{i}, 1, \text { Infinity }\}\right]= \\
& \mathrm{T} \text { p" } \mathrm{d}[\mathrm{p} " /(1-\mathrm{p},)] / \mathrm{dp} "=\mathrm{T} \text { p"/(1-p" })^{2}= \\
& \mathrm{T}\left(1-\mathrm{p}^{\prime}\right) / \mathrm{p}^{\prime 2} \text {. }
\end{aligned}
$$

According to [4] the frame transmission time $\mathrm{T}$ is $5.5 \mathrm{~ms}$. The final value of p' is not yet firmly decided. Directly based on [5] and discussions with engineers at ARINC, the manufacturers of VDL-2 radios, we use p' $=3(13 / 256)=39 / 256=0.152$, a value three times higher than that proposed in the SARPS for VDL-2. This value appears best according to the broad consensus of current research [5]. Consequently, $D_{\mathrm{s}}=0.202 \mathrm{~s}$.

Let "pd" represent the processing delay encountered by a message and $d$ the propagation delay experienced by that same message.

If the number of collisions, coll, is coll $=1$, the expected exponential backoff delay, $\mathrm{BD}$, is $2 \mathrm{~T} / 2=\mathrm{T}$.

If coll $=2, \mathrm{BD}=4 \mathrm{~T} / 2=2 \mathrm{~T}$. If coll $=3, \mathrm{BD}=8$ $\mathrm{T} / 2=4 \mathrm{~T}$. 


$$
\mathrm{RTD}_{1}=\mathrm{D}_{\mathrm{s}}+\mathrm{pd}+\mathrm{d}+\mathrm{pd}+\mathrm{d}+\mathrm{T}+
$$$$
\mathrm{D}_{\mathrm{s}}+\mathrm{pd}+\mathrm{d}+\mathrm{pd}
$$

$$
\begin{aligned}
& \mathrm{RTD}_{2}=\mathrm{D}_{\mathrm{s}}+\mathrm{pd}+\mathrm{d}+\mathrm{pd}+\mathrm{d}+\mathrm{T}+ \\
& \mathrm{D}_{\mathrm{s}}+\mathrm{pd}+\mathrm{d}+\mathrm{pd}+\mathrm{d}+2 \mathrm{~T} \\
& \mathrm{D}_{\mathrm{s}}+\mathrm{pd}+\mathrm{d}+\mathrm{pd}
\end{aligned}
$$

$$
\begin{aligned}
& \mathrm{RTD}_{\mathrm{i}}=\mathrm{i}\left(\mathrm{D}_{\mathrm{s}}+\mathrm{pd}+\mathrm{d}+\mathrm{pd}+\mathrm{d}\right)+\mathrm{D}_{\mathrm{s}} \\
& \left.+\mathrm{pd}+\mathrm{d}+\mathrm{pd}+\mathrm{T} \operatorname{Sum}\left[2^{\mathrm{j}-1},\{\mathrm{j}, 1, \mathrm{i})\right\}\right] \\
& \mathrm{D}^{\prime}=\left(\mathrm{D}+\mathrm{D}_{\mathrm{s}}\right)(1-\mathrm{p})+\operatorname{Sum}\left[\mathrm{RTD}_{\mathrm{i}} \mathrm{p}^{\mathrm{i}}(1-\mathrm{p}),\right. \\
& \{\mathrm{i}, 1, \text { Infinity }\}] . \\
& \mathrm{D}=2 \text { pd }+\mathrm{d} .
\end{aligned}
$$

$\left.\mathrm{RTD}_{\mathrm{i}}>\mathrm{i}\left(\mathrm{D}+\mathrm{D}_{\mathrm{s}}\right)+\mathrm{D}+\mathrm{D}_{\mathrm{s}}+\mathrm{T} \mathrm{Sum}\left[2^{\mathrm{j}-1},\{\mathrm{j}, 1, \mathrm{i})\right\}\right]=$ $\mathrm{i}\left(\mathrm{D}+\mathrm{D}_{\mathrm{s}}\right)+\mathrm{D}+\mathrm{D}_{\mathrm{s}}+\left(2^{\mathrm{i}}-1\right) \mathrm{T}$

$D^{\prime}>=\left(D+D_{s}\right)(1-p)+\operatorname{Sum}\left[\left((i+1)\left(D+D_{s}\right) p^{i}\right.\right.$ $(1-\mathrm{p}),\{\mathrm{i}, 1$, Infinity $\}]+$

$\operatorname{Sum}\left[\left(2^{\mathrm{i}}-1\right) \mathrm{T} \mathrm{p}^{\mathrm{i}}(1-\mathrm{p}),\{\mathrm{i}, 1\right.$, Infinity $\left.\}\right]=$

$\left(D+D_{s}\right)(1-p)\left[1+\operatorname{Sum}\left[(i+1) p^{i},\{i, 1\right.\right.$, Infinity $\left.\}\right]+$ $(1-p) T \operatorname{Sum}\left[\left(2^{\mathrm{i}}-1\right) \mathrm{p}^{\mathrm{i}},\{\mathrm{i}, 1\right.$, Infinity $\left.\}\right]=$

$\left(D+D_{s}\right)(1-p)\left(1+s^{\prime}\right)+(1-p) T[2 p /(1-2 p)-$ $\mathrm{p} /(1-\mathrm{p})]=$

$\left(D+D_{s}\right)(1-p)\left(1+s^{\prime}\right)+T[p /(1-2 p)]$

This sum s' is also an arithmetic-geometric series and may be handled as before:

$\mathrm{s}^{\prime}=\mathrm{d}\left[\operatorname{Sum}\left[\mathrm{p}^{\mathrm{i}},\{\mathrm{i}, 1\right.\right.$, Infinity $\left.\left.\}\right]\right] / \mathrm{dp}=\mathrm{d}[\mathrm{p} /(1-\mathrm{p})-$ $\mathrm{p}] / \mathrm{dp}=1 /(1-\mathrm{p})^{2}-1$.

(3) $\mathrm{D}^{\prime}>\left(\mathrm{D}+\mathrm{D}_{\mathrm{s}}\right)(1-\mathrm{p}) /(1-\mathrm{p})^{2}+\mathrm{T}[\mathrm{p} /(1-2 \mathrm{p})]=$ $\left(\mathrm{D}+\mathrm{D}_{\mathrm{s}}\right) /(1-\mathrm{p})+\mathrm{T}[\mathrm{p} /(1-2 \mathrm{p})]$,

the final term due to exponential back-off is so small as to be negligible.

Since we used the expected binary exponential back-off and expected startup delays, while (3) may be true more than on average, we are only permitted to say that (3) is obeyed on average. The question has been raised as to whether the increase in performance of PCSMA over VDL-2 is due to an unfair comparison between a PCSMA network utilizing two channels versus a VDL-2 network using just one. With the foregoing analysis, it is possible to determine whether there is still a performance gain if we assume the PCSMA network utilizing two channels (data + cnctrans) competes with a VDL-2 network using just two VDL-2 data channels as well. In that case, our inequality (3) still applies, but with a smaller value of $\mathrm{p}$. Since the simulations were performed so that the mean traffic doubles, the value of $p$ for a prior simulation will apply for the next simulation with double the mean traffic. Unfortunately, we may only compare performance for the last two sets of simulations.

\section{Retransmission Analysis Conclusions}

- Retransmission analysis reveals that if D is the mean ETE delay for a FT network, then $\mathrm{D}^{\prime}>\left(\mathrm{D}+\mathrm{D}_{\mathrm{s}}\right) /(1-\mathrm{p})$ is the mean ETE delay for a CSMA (VDL-2) network, where " $p$ " is the overall probability of a collision.

- " $p$ " for simulations (I - III) is 11.4, 20.5 , and 33.4 percent, which in the last two sets yields respective delay improvements over a comparable VDL-2 simulation of at least 31.2 and 11.9 percent. While this improvement may seem modest, it is important to remember that the calculation of PCSMA's performance is conservative while that of VDL-2's is generous. Based on other's research, the author estimates that given the traffic load of this simulation, CPDLC latencies using VDL-2 in this simulation would be between 2.5 and 3 seconds. In this paper, we were just trying to show that PCSMA does perform better in terms of latency.

Although it may seem counterintuitive that a single PCSMA data channel can outperform two VDL-2 data channels, it is not surprising given that the efficiency of a single CSMA link is only about $33 \%$, while the PCSMA data channel is highly efficient. The usage of two or more VDL-2 channels will increase as VDL-2 is further deployed. PCSMA will perform even better when three or more PCSMA data channels share the single lowly-utilized cnctrans channel. 


\section{Conclusions}

One thing is obvious from a comparison of Runs I through III with IV through VI: PCSMA works. PCSMA would serve the same purpose for aeronautical communications traffic as the traffic light does for automobile traffic - to prevent collisions. In the event that it is critical to receive messages without many retransmissions or with minimum latency, PCSMA may be very useful. Acknowledgments and retransmissions increase the amount of traffic, increasing the number of collisions and worsening communications throughput.

Currently there is an average of 12,000 flights per day in the NAS. Forecasts suggest that air traffic will triple over the next 20 years. Simulation studies have been performed that show that there is an upper limit to the number of aircraft that may be supported using VDL-2, i.e., traditional CSMA [4]. The limitation exists because of the inherent inefficiencies present in contentious, disorderly CSMA. Plans are underway to replace VDL-2 (which has barely been deployed) as the national aviation data link scheme with VDL-3, referred to as NEXCOM, based on time division multiple access (TDMA). This transition may be most expensive and somewhat sudden. However, small add-on modules could be manufactured to mate with existing VDL-2 radios to implement PCSMA, thereby extending the lifetime of VDL-2. Moreover, engineers now have great experience in building CSMA-based aeronautical subsystems.

An operational requirement for VDL-2 is that 95\% of the CPDLC messages must be received within 3 seconds after they are generated. If this requirement is unmet, this failure represents a breakdown in VDL-2. Since PCSMA may be used to determine breakdown traffic conditions for largescale simulations, it appears as though this simulation method could be used to obtain an upper limit for the performance of CSMA or as justification for further research into the use of PCSMA. The number of frequencies needed to support VDL-2 or VDL-3 traffic within a geographic region is dependent upon a number of factors including the amount of communications traffic and the desired one-way transit time [6]. For example, it is generally acknowledged that not just one, but several frequencies (channels) (perhaps as many as 7 , as are being used to support the few existing newly VDL-2 equipped planes in Florida today) must be allocated for a practical, nationwide implementation of VDL-2. Currently, no research has been performed to determine the frequency allocation adequacy for VDL-2 for supporting the NAS (1 x NAS) or twice the data/air-traffic volume of the NAS $(2 \times$ NAS) or $3 \times$ NAS. The simulations that have been conducted herein are significant because in them the communications of $10 \%$ of the air traffic in the NAS was supported using just two frequencies! Also, this paper should establish that we can obtain bounds for the average delays for aggregate traffic in 1, 2 or $3 \times$ NAS. The results of these OPNET simulations may be compared to the output of Task Order 14 of NASA Contract No.

NAS3-99165, the Future Aeronautical Subnetwork Traffic Emulator for Communications, Navigation, Surveillance (FASTE-CNS), which calculates the VDL-2 and VDL-3 frequency requirements needed to support the geographical regions defined in a specified air traffic density profile that can include the entire NAS [6].

A large network has been constructed for this simulation. It may also be used for a simulation of VDL-3, which may be compared to these baseline simulations of PCSMA. Moreover, once we have a large-scale network including nearly 12,000 flights per day, we can see the improvement made as a result of augmenting the air traffic management using satellite communications. With the new acquisition of much greater computing power for simulation, plans are underway to expand the number of daily flights to between 5,000 and 10,000 , and to use more precise message sizes and frequencies. We intend using versions of this network as a foundation for simulations involving ground station gap analysis and resolution through satellite communications. Such large-scale, aggregate-realistic networks would never be possible if we were to model every detail of the protocol stack. Indeed, most OPNET ATN simulations model only a small number of aircraft. If they do model more aircraft, often they are stationary, depicting a snapshot in time. Moreover, each aircraft in our simulations has an active transmitter and receiver, adding to realism. Under the VAMS program, agency-wide plans are underway at NASA to create a realistic, detailed, runway-to-runway simulation of an entire day in the 
NAS, with aircraft flying realistic trajectories and being represented as software agents. The simulations are intended to facilitate design and tradeoff studies of system level concepts within the NAS [7]. This High Level Architecture (HLA)-based national simulation will not be in the OPNET environment. However, it appears as though using the approach of this paper, we will be able to collect aggregate results in OPNET to which the results of the new national simulation may be compared. It appears that only by adopting the methodology shown in this paper will we ever be able to acquire meaningful aggregate results in a large-scale OPNET simulation that runs in a week or less on a reasonably powerful computer.

It is admitted that communication on the cnctrans reservation channel was not sufficiently modeled. In the simulations it is assumed that the cnctrans packets have size zero. In reality, they have payload on the order of one byte, which is very small compared to the traffic on the data channel. Moreover, no access scheme had been specified for communication on the reservation channel since the probability of collision there was zero. Actually, the author believes that ordinary CSMA would be a good access scheme for the reservation channel due to its low traffic volume and probability of collision. Hence, the name "Prioritized CSMA" may be retained.

The simulation of communication was effected without the complexity involved in the aeronautical telecommunications network. It is desirable to identify communications systems that work and can be proven through simulation. Presently, there is little simulation research supporting nationwide usage of the VDL modes. In this research, continuous communication was achieved in a realistic nationwide aviation scenario. It is difficult to even begin to convincingly do this for communications based on the ATN stack. The results from PCSMA simulations were related to those of corresponding would-be VDL-2 simulations through modeling relations because the author believes that to implement accurate, corresponding VDL-2 simulations would involve undue effort resulting in unbearably long simulation run times. An important result of this research is not just the aggregate outputs gathered, but the mere fact that this new data link architecture appears to work in a fairly realistic and robust simulated environment. Actually, simulating a design before deploying it is really what should have been done in the NAS rather than simply choosing an architecture without testing it on future as well as current load, manufacturing it, deploying it, and then simulating it after committing to it. This research is justified because there is no similar research involving the simulation in a nationwide scenario of a new, or, for that matter, of any aviation data link.

\section{References}

[1] Daryl C. Robinson, "CSMA versus Prioritized CSMA for Air Traffic Control Improvement," IEEE Aerospace Conference, January 2002.

[2] Final Report of RTCA Task Force 3 on Free Flight Implementation, October 26, 1995.

[3] ICAO VDL-2 Standards and Recommended Practices [SARPS].

[4] Brian T. Hung, "Modeling and Simulation of an Aeronautical CSMA Subnetwork," OPNETWORK 2001, August 2001.

[5] Bob Eberlein and Mike Shorthose, "European ATN Simulation VDL Mode 2 Simulation Report," EUROCONTROL, April 2000.

[6] Computer Networks \& Software, Inc., System Specification to NASA Glenn Research Center for the FASTE-CNS, May 2002.

[7] VAMS Project Plan v8.0, 11/20/2001. 
Public reporting burden for this collection of information is estimated to average 1 hour per response, including the time for reviewing instructions, searching existing data sources, gathering and maintaining the data needed, and completing and reviewing the collection of information. Send comments regarding this burden estimate or any other aspect of this collection of information, including suggestions for reducing this burden, to Washington Headquarters Services, Directorate for Information Operations and Reports, 1215 Jefferson Davis Highway, Suite 1204, Arlington, VA 22202-4302, and to the Office of Management and Budget, Paperwork Reduction Project (0704-0188), Washington, DC 20503.

\begin{tabular}{|l|c|c|c|}
\hline 1. AGENCY USE ONLY (Leave blank) & $\begin{array}{c}\text { 2. REPORT DATE } \\
\text { February } 2005\end{array}$ & $\begin{array}{r}\text { 3. REPORT TYPE AND DATES COVERED } \\
\text { Technical Memorandum }\end{array}$ \\
\hline 4. TITLE AND SUBTITLE & 5. FUNDING NUMBERS
\end{tabular}

Dual Purpose Simulation: New Data Link Test and Comparison With VDL-2

6. $\operatorname{AUTHOR(S)}$

Daryl C. Robinson

WBS-22-727-01-06

7. PERFORMING ORGANIZATION NAME(S) AND ADDRESS(ES)

National Aeronautics and Space Administration

John H. Glenn Research Center at Lewis Field

Cleveland, Ohio 44135-3191

8. PERFORMING ORGANIZATION REPORT NUMBER

E-14893

9. SPONSORING/MONITORING AGENCY NAME(S) AND ADDRESS(ES)

10. SPONSORING/MONITORING

AGENCY REPORT NUMBER

National Aeronautics and Space Administration

Washington, DC 20546-0001

NASA TM-2005-213385

\section{SUPPLEMENTARY NOTES}

Prepared for the 21st Digital Avionics Systems Conference (DASC 2002) cosponsored by the American Institute of Aeronautics and Astronautics and the Institute of Electrical and Electronics Engineers, Irvine, California, October 27, 2002. Responsible person, Daryl C. Robinson, organization code 5610, 216-433-3553.

12a. DISTRIBUTION/AVAILABILITY STATEMENT

12b. DISTRIBUTION CODE

Unclassified - Unlimited

Subject Categories: 04 and 32

Distribution: Nonstandard

Available electronically at http://gltrs.grc.nasa.gov

This publication is available from the NASA Center for AeroSpace Information, 301-621-0390.

13. ABSTRACT (Maximum 200 words)

While the results of this paper are similar to those of previous research, in this paper technical difficulties present there are eliminated, producing better results, enabling one to more readily see the benefits of Prioritized CSMA (PCSMA). A new analysis section also helps to generalize this research so that it is not limited to exploration of the new concept of PCSMA. Commercially available network simulation software, OPNET version 7.0, simulations are presented involving an important application of the Aeronautical Telecommunications Network (ATN), Controller Pilot Data Link Communications (CPDLC) over the Very High Frequency Data Link Mode 2 (VDL-2). Communication is modeled for essentially all incoming and outgoing nonstop air traffic for just three United States cities: Cleveland, Cincinnati, and Detroit. The simulation involves 111 Air Traffic Control (ATC) ground stations, 32 airports distributed throughout the U.S., which are either sources or destinations for the air traffic landing or departing from the three cities, and also 1,235 equally equipped aircraft - taking off, flying realistic free-flight trajectories, and landing in a 24-hr period. Collision-less PCSMA is successfully tested and compared with the traditional CSMA typically associated with VDL2. The performance measures include latency, throughput, and packet loss. As expected, PCSMA is much quicker and more efficient than traditional CSMA. These simulation results show the potency of PCSMA for implementing low latency, high throughput and efficient connectivity. Moreover, since PCSMA outperforms traditional CSMA, by simulating with it, we can determine the limits of performance beyond which traditional CSMA may not pass. We are testing a new and better data link that could replace CSMA with relative ease. Work is underway to drastically expand the number of flights to make the simulation more representative of the National Aerospace System.

14. SUBJECT TERMS

Aeronautical simulation; Datalink; NAS; VDL-2; PCSMA; CPDLC; CSMA; TDMA

17. SECURITY CLASSIFICATION OF REPORT

Unclassified
18. SECURITY CLASSIFICATION OF THIS PAGE

Unclassified
19. SECURITY CLASSIFICATION OF ABSTRACT

Unclassified
15. NUMBER OF PAGES 16 16. PRICE CODE 20. LIMITATION OF ABSTRACT

Standard Form 298 (Rev. 2-89)

Prescribed by ANSI Std. Z39-18 298-102 

